\title{
Seismic Performance Evaluation of Boil-Off Gas Compressor in LNG Terminal
}

\author{
Hyo-Sang Park and Tae-Hyung Lee*
}

Department of Civil Engineering, Konkuk University, Seoul, Korea

\begin{abstract}
Liquefied natural gas (LNG) terminals, one of the lifeline facilities, need to be protected by a proper seismic design against extreme earthquakes. An LNG terminal consists of a series of process facilities that are connected by pipelines of various sizes. Boil-off gas (BOG) compressor is one of the critical process facilities whose failure will cause the functional failure of the LNG terminal. Process facilities, including BOG compressor, other than LNG storage tanks and pipes, have not been a major concern in terms of the seismic performance evaluation. In this study, the seismic performance of a BOG compressor is evaluated and the seismic fragility functions are presented. An integrated system of a BOG compressor is modeled by a 3 dimensional finite element modeling scheme. A series of time history analyses are conducted to monitor the behavior of anchor bolts, one of the most critical elements in the BOG compressor. To develop fragility curves, a set of 20 ground motions are selected from a database of the historic earthquake accelerations. Fragility curves are developed based on the maximum likelihood estimation approach with respect to the strength limit states. When an earthquake load is applied to the BOG compressor, the main motor is likely to overturn and the flywheel is likely to slide, and, consequently, anchor bolts will be subjected to tension and shear force, respectively. It is concluded that the BOG compressor is safe against the design level earthquake
\end{abstract}

Keywords: BOG compressor, LNG terminal, nonlinear time history analysis, seismic fragility, seismic performance, uncertainty.

\section{INTRODUCTION}

A liquefied natural gas (LNG) receiving terminal (or just LNG terminal for short) is a facility where LNG is unloaded from shipment, stored, regasified, and exported to distribution terminals. Since LNG is a hazardous material due to its flammability after vaporization, an LNG terminal has to be designed such that the leakage of LNG is prevented under various environmental hazards such as an earthquake or a tsunami. In addition to a direct hazard, its societal and economic impacts would be considerable to nearby urban regions when an LNG terminal is damaged and gas is leaked.

Even if a facility is seismically designed, it is still vulnerable to earthquakes stronger than the design earthquake. Furthermore, an earthquake smaller than the design earthquake may damage the facility if the ductile design concept is applied. Therefore, it is important to understand the seismic capacity of the facility over a wide range of earthquake intensities. Seismic fragility analysis is one of the most common approaches to evaluate the seismic capacity of structures such as buildings, bridges, nuclear power plant, and lifelines [1-6].

An LNG terminal consists of various process facilities, mechanical equipment, and pipelines. Research on the

*Address correspondence to this author at the Department of Civil Engineering, Konkuk University, Seoul, Korea; Tel: +82-2-450-4093;

Fax: +82-2-450-4093; E-mail: thlee@konkuk.ac.kr evaluation of seismic performance has been focused on LNG storage tanks and pipelines $[7,8]$. Seismic design regulations or guidelines are also established only for tanks and pipelines [9-11]. The other process facilities such as compressors and vaporizers are rarely a subject of seismic analysis. However, the evaluation of the seismic performance of the LNG terminal requires the evaluation of all process facilities.

The purpose of this paper is to evaluate the seismic performance of a boil-off gas (BOG) compressor in terms of its fragility functions. One of the typical BOG compressors in operation in a Korean LNG terminal is selected and its 3dimensional finite element model is built using a commercial program. Using a set of 20 selected ground motions, time history analysis is performed for various levels of ground motion intensities. Finally, fragility curves for specific limit states are developed using the maximum likelihood estimation method.

\section{DESCRIPTIONS OF BOG COMPRESSOR}

An LNG terminal receives, stores, and regasifies natural gas. BOG is gas vaporized from LNG when heat is introduced, pressure is lowered, or some other reasons. If BOG is not properly treated, the pressure in the tank and pipeline rises and causes a problem in the whole process of regasification. Therefore, BOG is re-liquified and sent to the storage tank, or sent to the vaporization process units. A BOG compressor puts pressure on BOG. Fig. (1) shows a schematic view of the major process facilities in an LNG. Fig. (2) 


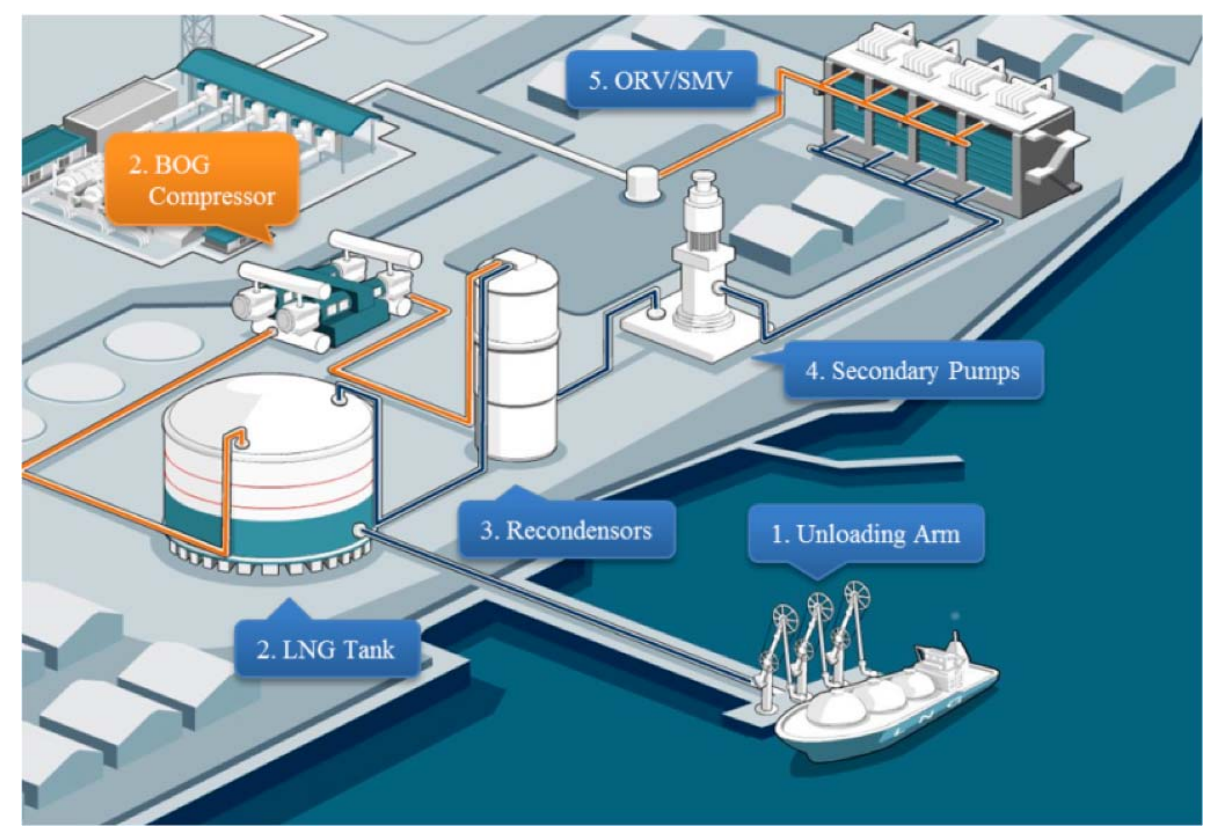

Fig. (1). Concept map of an LNG receiving terminal.

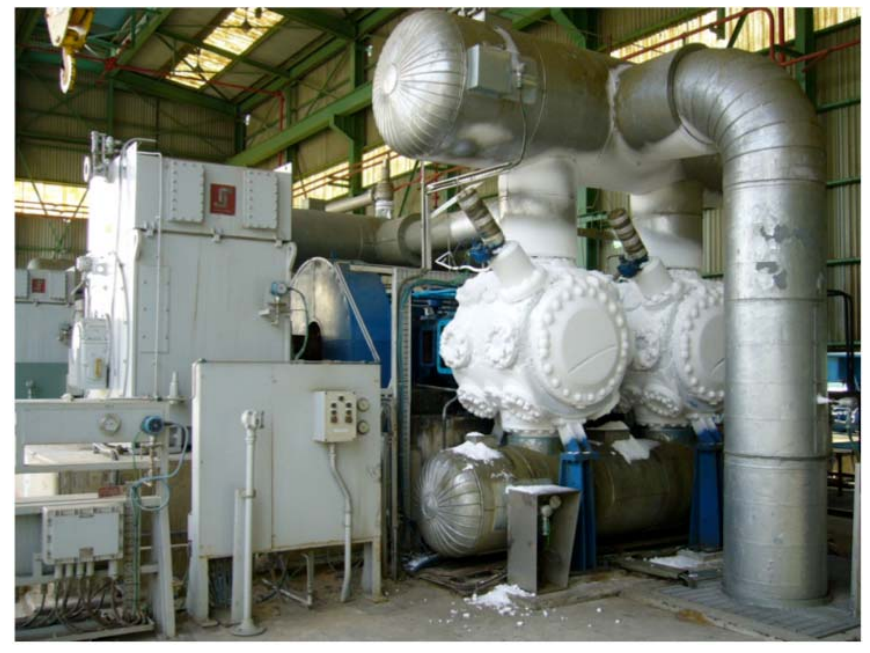

Fig. (2). Horizontal type BOG compressor.

Table 1. Properties of various anchor bolts.

\begin{tabular}{|c|c|c|}
\hline Type & Position & Area $\left(\mathbf{m m}^{\mathbf{2}}\right)$ \\
\hline \hline A & Flywheel & 642 \\
\hline B & Distance Piece & 236 \\
\hline C & Cylinder & 339 \\
\hline D & Cylinder & 429 \\
\hline E & Main Motor & 762 \\
\hline
\end{tabular}

shows a picture of the BOG compressor in operation in one of the Korean LNG terminals and selected as the example compressor of this study.

The BOG compressor consists of compressor units and the foundation, with the compressor units fastened to the foundation using anchor bolts. The compressor consists of 4 cylinders, 4 dampers, a main motor, and the flywheel. It is noted that the flywheel changes a rotational motion to a reciprocating motion. The foundation is a reinforced concrete structure with a deep thickness. Fig. (3) shows a schematic view of the BOG compressor where major mechanical parts and dimensions of the foundation are indicated. Five types of anchor bolts are used for different mechanical parts of the BOG compressor. Table 1 lists anchor bolts for different mechanical parts and their sizes.

\section{SEISMIC PERFORMANCE EVALUATION}

\subsection{Seismic Design Regulations for LNG Terminal}

Most of the process facilities in the Korean LNG terminal are seismically designed. Unlike the LNG storage tank, a seismic design regulation explicitly for a BOG compressor is not available and the Uniform Building Code [12] and NFPA 59A [13] are utilized to design such a process facility. Process facilities including the storage tank are designed against the Operational Basis Earthquake (OBE) and Safe Shutdown Earthquake (SSE) according to NFPA 59A. The OBE ground motion at a site is defined as the lesser of ground motion with a $10 \%$ probability of exceedance within a 50 year period (475 year return period) or two-thirds of the Maximum Considered Earthquake (MCE) ground motion. In NFPA 59 [13], the MCE is defined as ground motion having a $2 \%$ probability of exceedance within a 50 year period (2475 year return period). The SSE ground motion at a site is defined as the lesser of $1 \%$ probability of exceedance within a 50 year period (4975 year return period) or two times the OBE. The design objective for SSE is to protect the facility by limiting seismic damage and to store LNG safely. The BOG compressor considered in this study is designed for SSE where the design ground accelerations are $0.2 \mathrm{~g}$ and $0.13 \mathrm{~g}$ in the horizontal and vertical directions, respectively. 


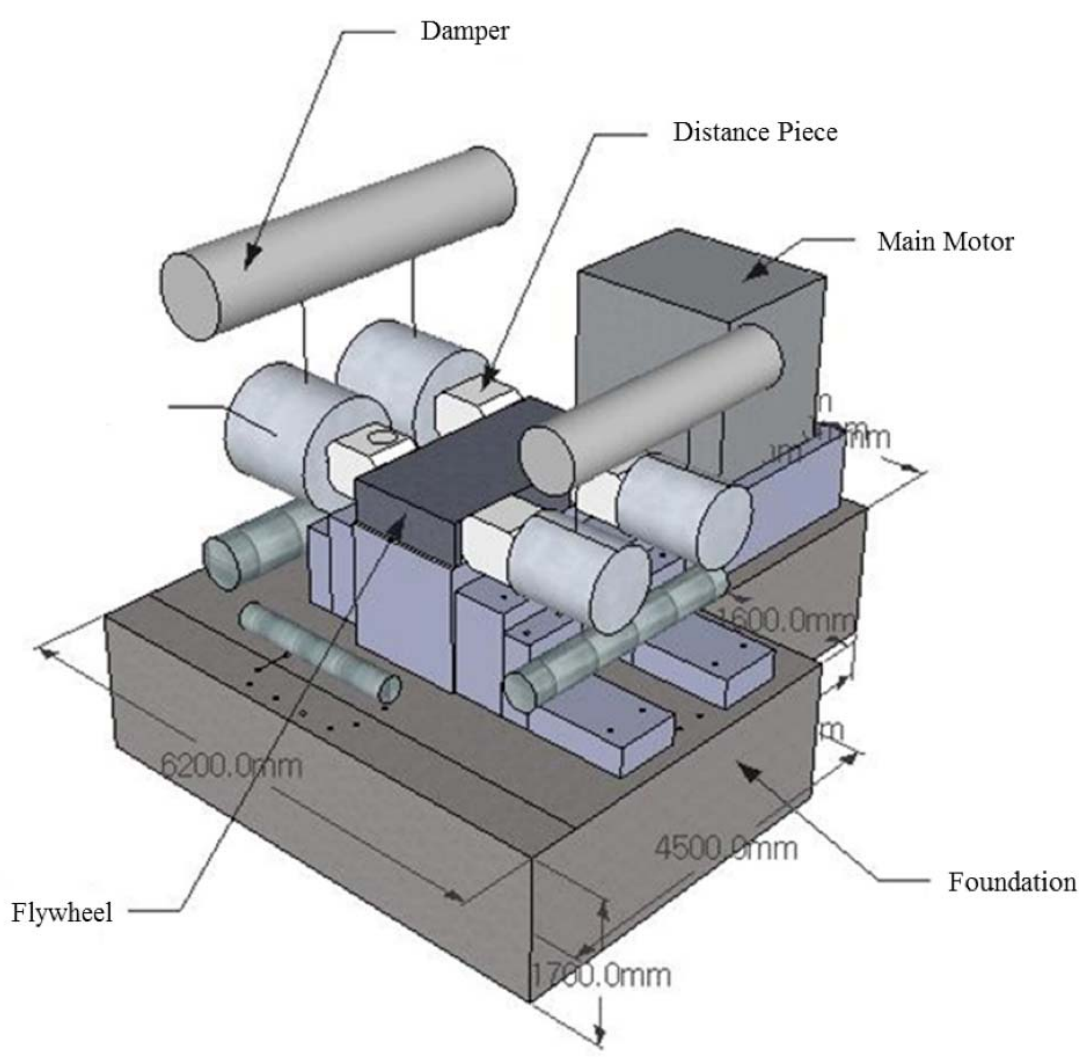

Fig. (3). Mimetic diagram of the BOG compressor.

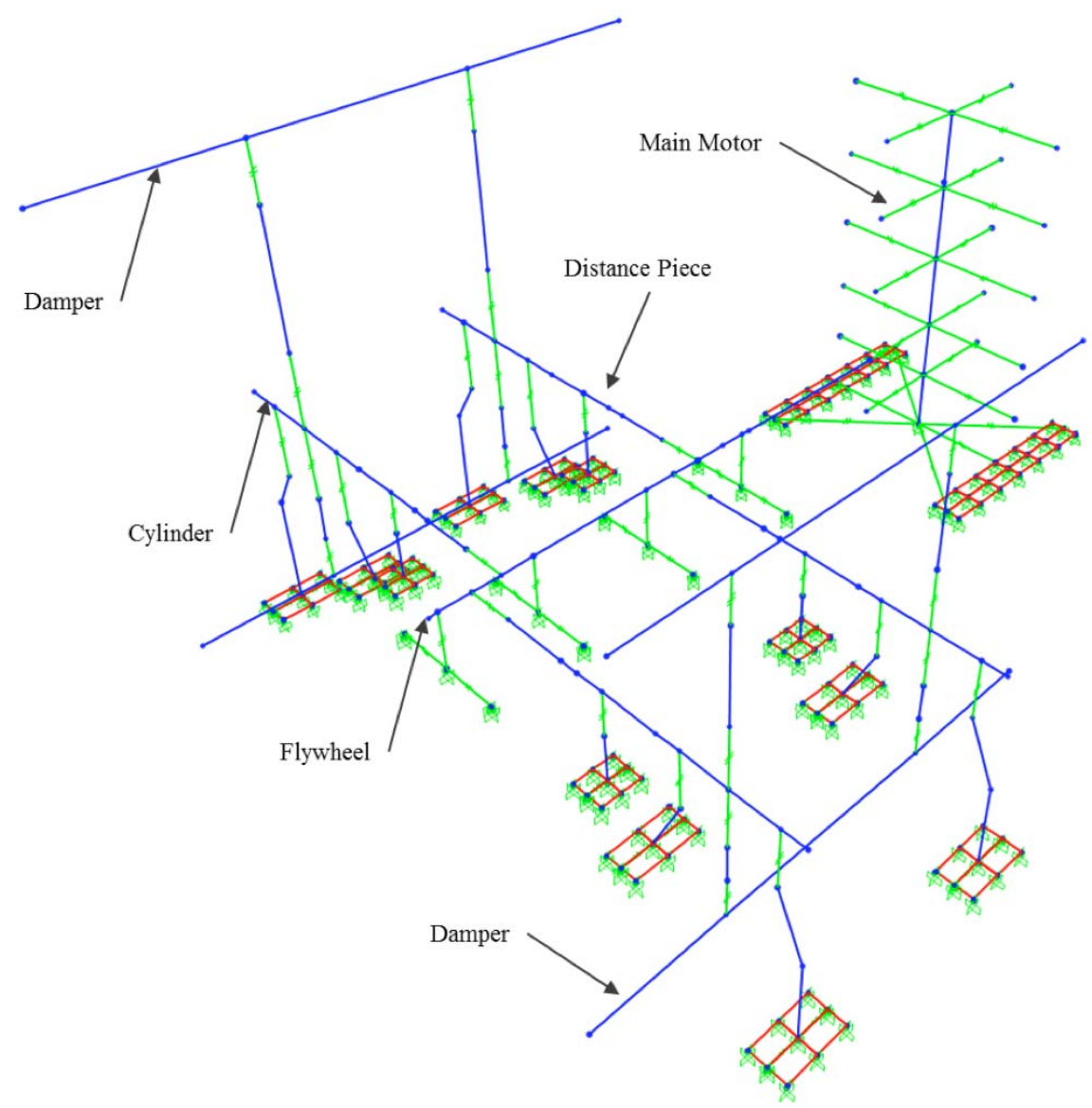

Fig. (4). Modeling of BOG compressor. 
a)

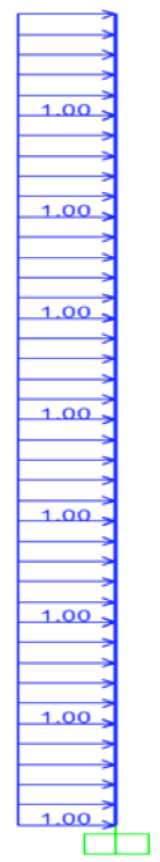

b)

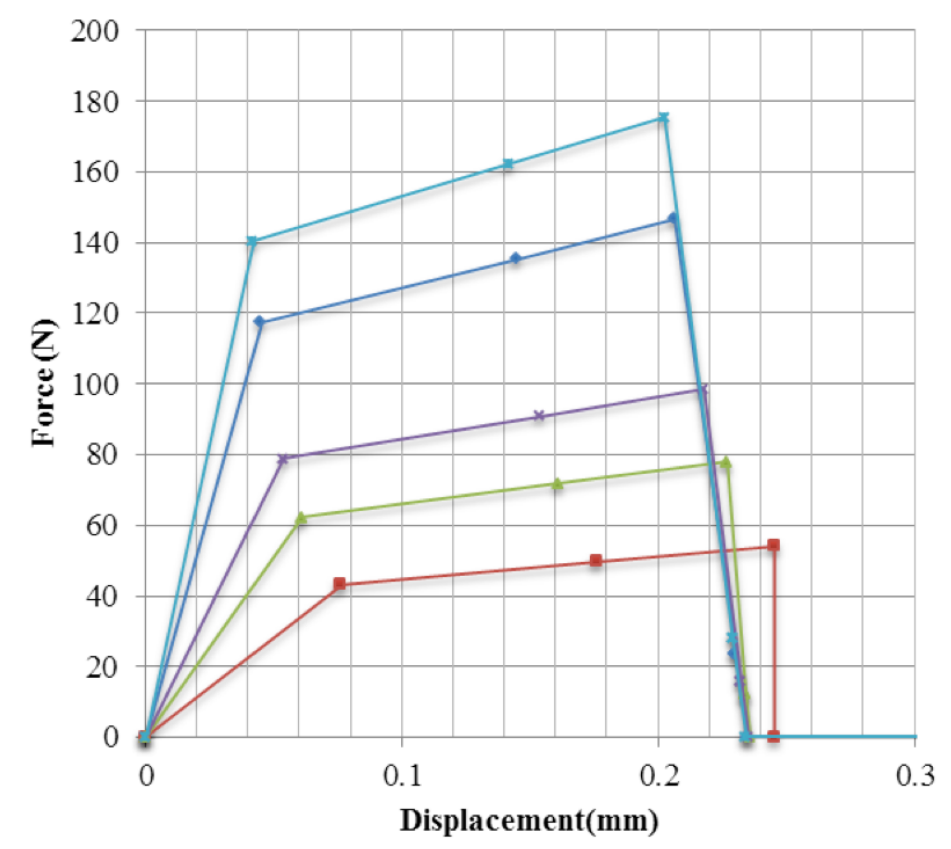

$\rightarrow$ A Type

- - B Type

$\leadsto$ C Type

* D Type

- E Type

Fig. (5). Pushover result of anchor bolt : a) distributed load (N) and b) pushover result.

The Korea Hydro and Nuclear Power Co. has applied the SSE measure to $0.2 \mathrm{~g}$ on operational and constructing nuclear power plants considering the seismicity in South Korea. It corresponds to an earthquake with the return period of 10,000 years. The same SSE is used to design LNG terminal facilities $[14,15]$.

\subsection{Finite Element Modeling of BOG Compressor}

The finite element model of the BOG compressor is developed using a commercial program, SAP2000 (version 15) [16]. It should be noted that the hand-written drawings of the compressor are reviewed to collect pieces of information required to develop a finite element model. Basically, all components of the compressor are modeled using a beamtype element. The reinforced concrete foundation and base plates encased by the foundation concrete are assumed rigid and are modeled as support conditions. Base plates are assumed to be resistant only to the bearing force. Anchor bolts that fasten base plates are assumed to be resistant to tensile and shear forces developed by overturning and sliding of the compressor, respectively. The base plate is modeled using Gap Element in SAP2000 which is defined only in a compressive region while the anchor bolt is modeled using Multi-Linear Plastic Element in SAP2000 which defines nonlinear material models in tensile and shear modes. It is assumed that the anchor bolt is not subjected to compression. It should be noted that the friction between the foundation and base is neglected. The effect of rotating or reciprocating mechanical parts in the compressor are not considered in the modeling according to Kubr and Zeman [17]. Fig. (4) shows the finite element model of the BOG compressor with the labels of major mechanical parts.

The tensile behavior of the anchor bolt is dictated by a bilinear steel material model defined by the yield strength, ultimate strength, and their corresponding strains. The shear force-deformation relation of the anchor bolt is developed by a pushover analysis where the bearing force induced by the base plate is simulated. Fig. (5) shows the finite element model of the anchor bolt with a uniformly distributed lateral load and the pushover analysis results for various bolt types.

\subsection{Application of Ground Motions}

Seismic performance of the BOG compressor is evaluated by time history analyses. The seismic response of a structure calculated by a time history analysis varies according to the input ground motion time history. Therefore, the ground motion time histories should be carefully selected for the purpose of the analysis. In this study, twenty recorded ground acceleration time histories are selected from the strong motion database provided by the Pacific Earthquake Engineering Research (PEER) Center [18]. The ground motions are selected among damaging historic earthquakes worldwide such that response spectra show wide range of spectral accelerations. A selected ground motion includes two horizontal and a vertical components where they are scaled such that the peak ground acceleration (PGA) of the vector sum of the two horizontal components is $0.2 \mathrm{~g}$ and PGA of the vertical component is $0.13 \mathrm{~g}$ as the seismic design regulation specifies. Fig. (6) shows the response spectra of the selected ground motions where the orange line indicate the average response spectrum of them. It is noted that PGA of all ground motions are scaled to $0.2 \mathrm{~g}$.

A wide range of earthquake intensities, namely PGA, is considered to evaluate the seismic performance of the BOG compressor. The ground acceleration profiles are scaled again so that the PGA of the sum of the horizontal components ranges from $0.2 \mathrm{~g}$ to $8.0 \mathrm{~g}$ where the vertical component is scaled accordingly. Table 2 shows the magnitude and PGAs of all directional components of the selected set of ground motions. 


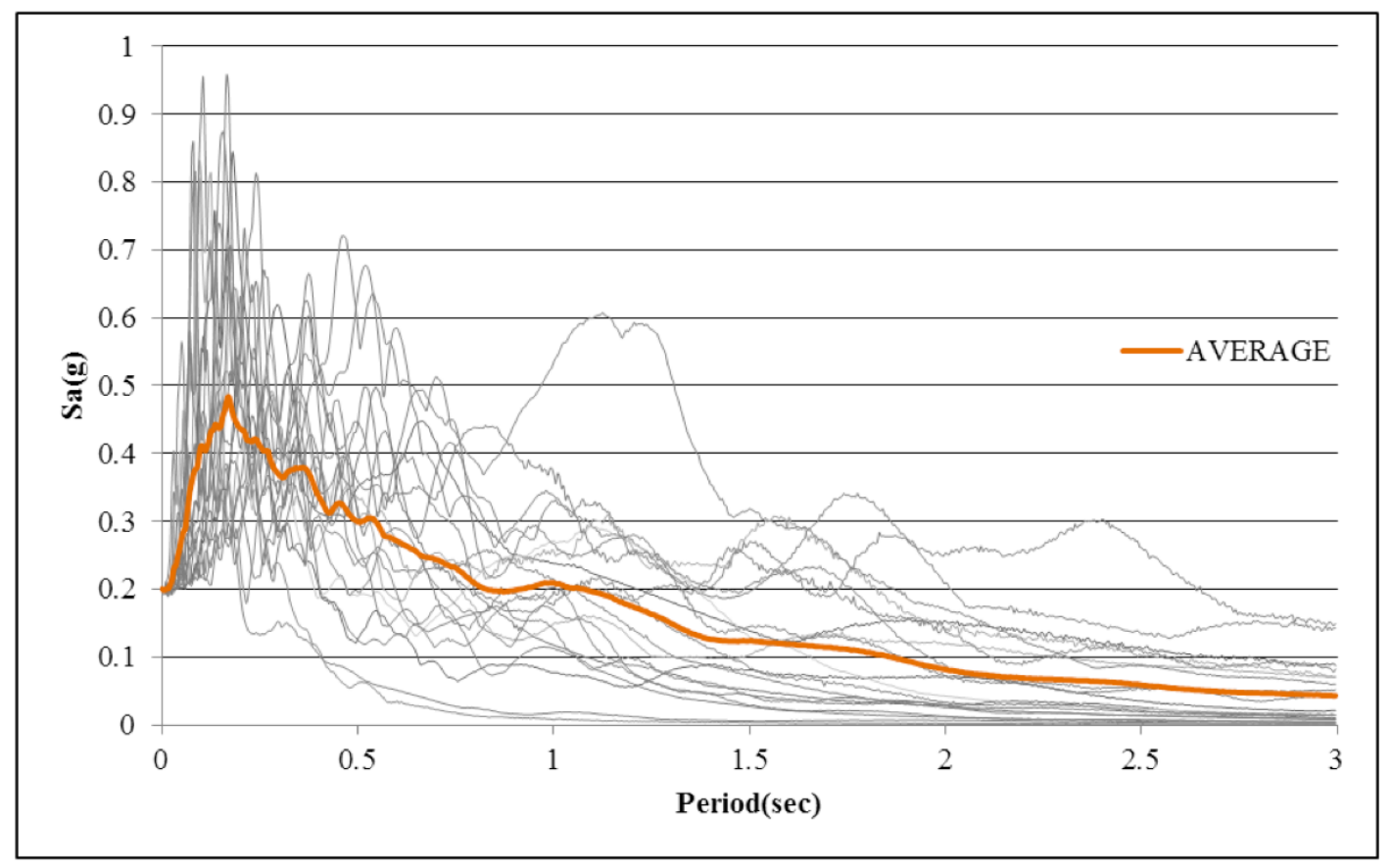

Fig. (6). Acceleration response spectrum.

Table 2. Selected ground motions.

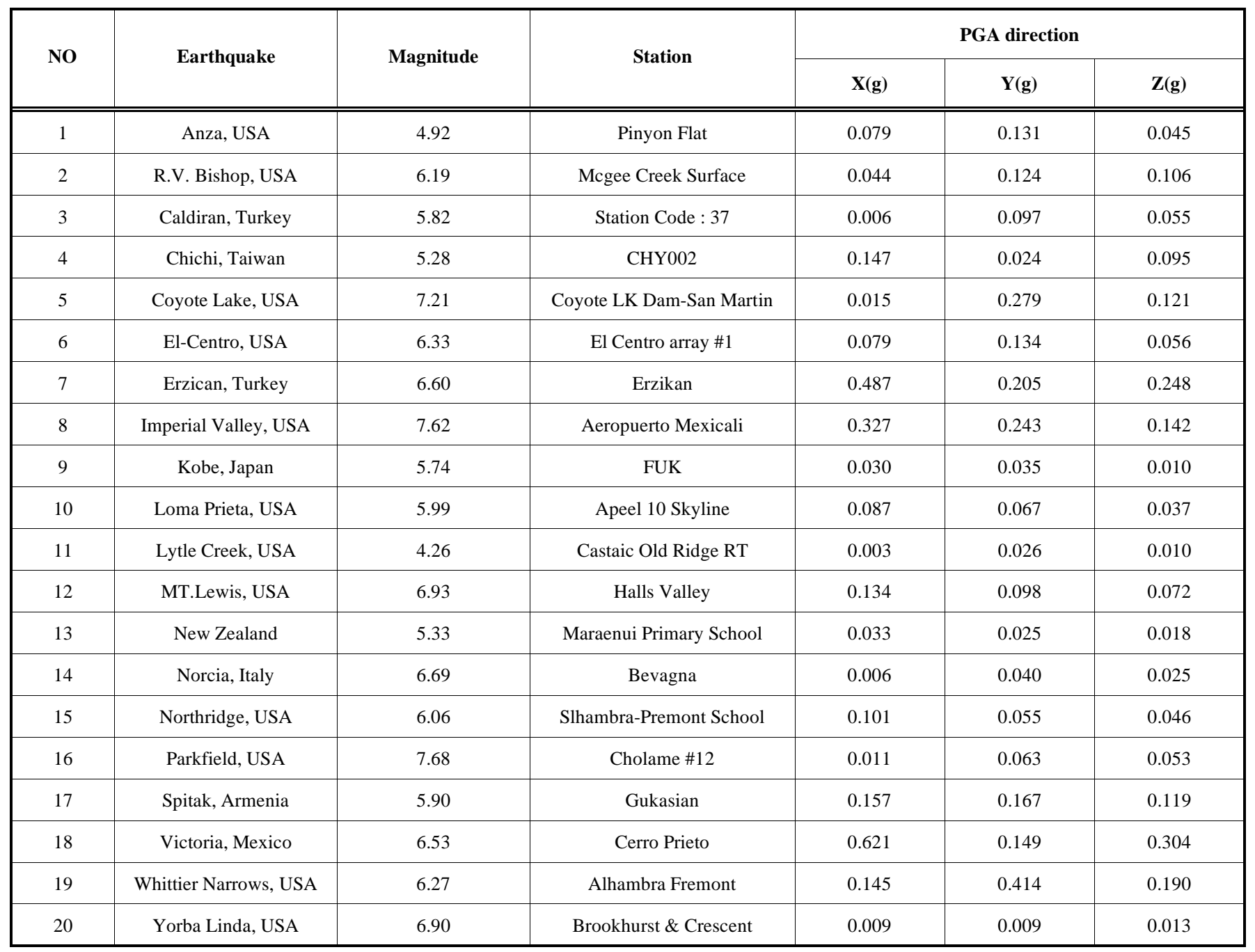




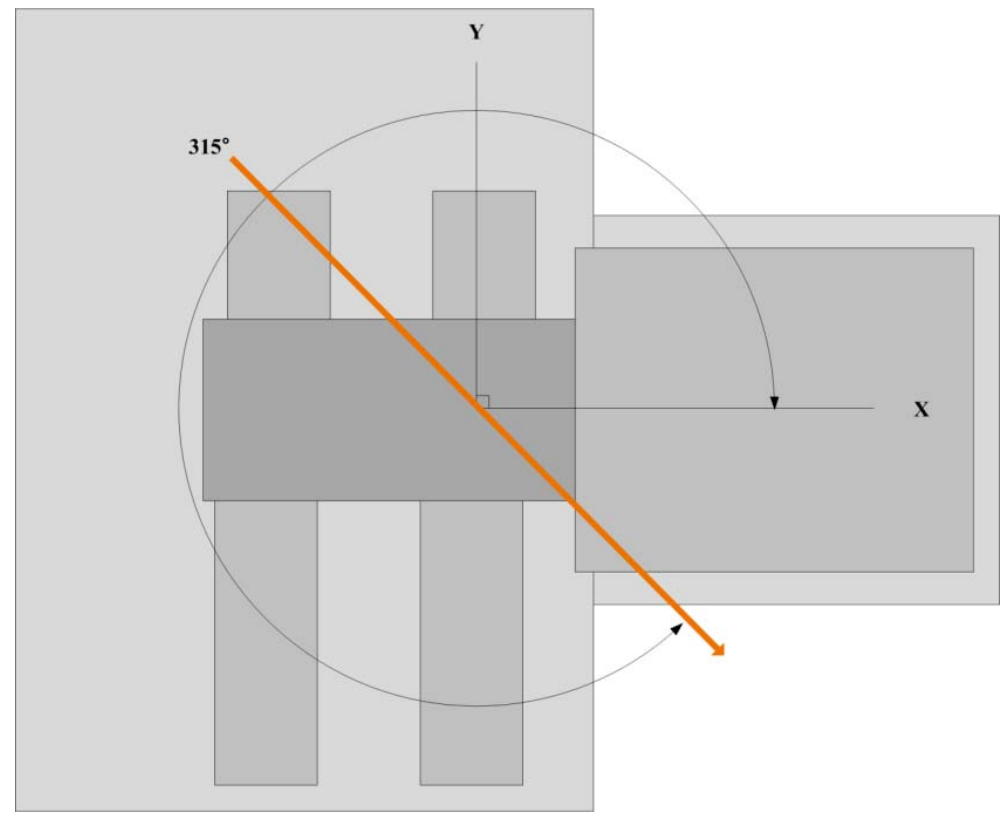

Fig. (7). Direction of the seismic load application to the BOG compressor.

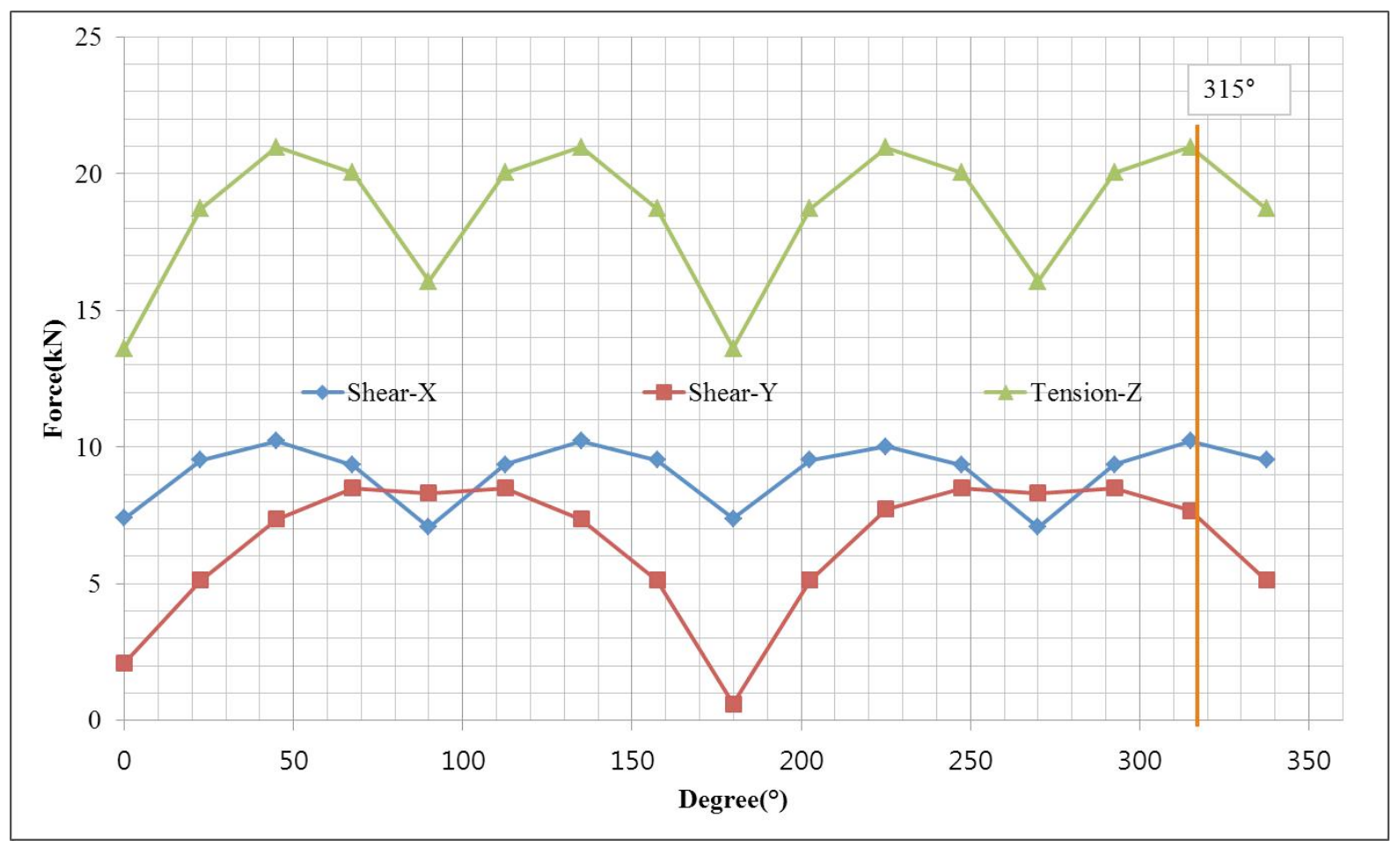

Fig. (8). Forces in the anchor bolts due to variations in the seismic loading direction.

Since the BOG compressor is an irregular structure, its vibrational modes may include complex mode shapes. Also, the horizontal application direction of the ground motion may affect the response of the compressor. Sine waves are applied to the compressor in various horizontal directions to determine the most influential direction where the largest response is calculated. Fig. (7) shows the variation of the maximum forces in the anchor bolts in $\mathrm{X}, \mathrm{Y}$, and $\mathrm{Z}$ directions for various application directions. It is observed that the 315 degrees from the $\mathrm{X}$-axis is the most influential direction as indicated in Fig. (8). Accordingly, all the horizontal ground motions are applied so that the vector sum of the two horizontal components is applied in 315 degrees in the following time history analyses.

\subsection{Time History Analysis Results}

\subsubsection{The Interpretation of Eigenvalue Analysis}

Eigenvalue analysis of the BOG compressor is performed to understand its dynamic characteristics. Fig. (9) shows the first four vibrational mode shapes and the corresponding natural periods. The compressor is a 'stiff' structure as the 

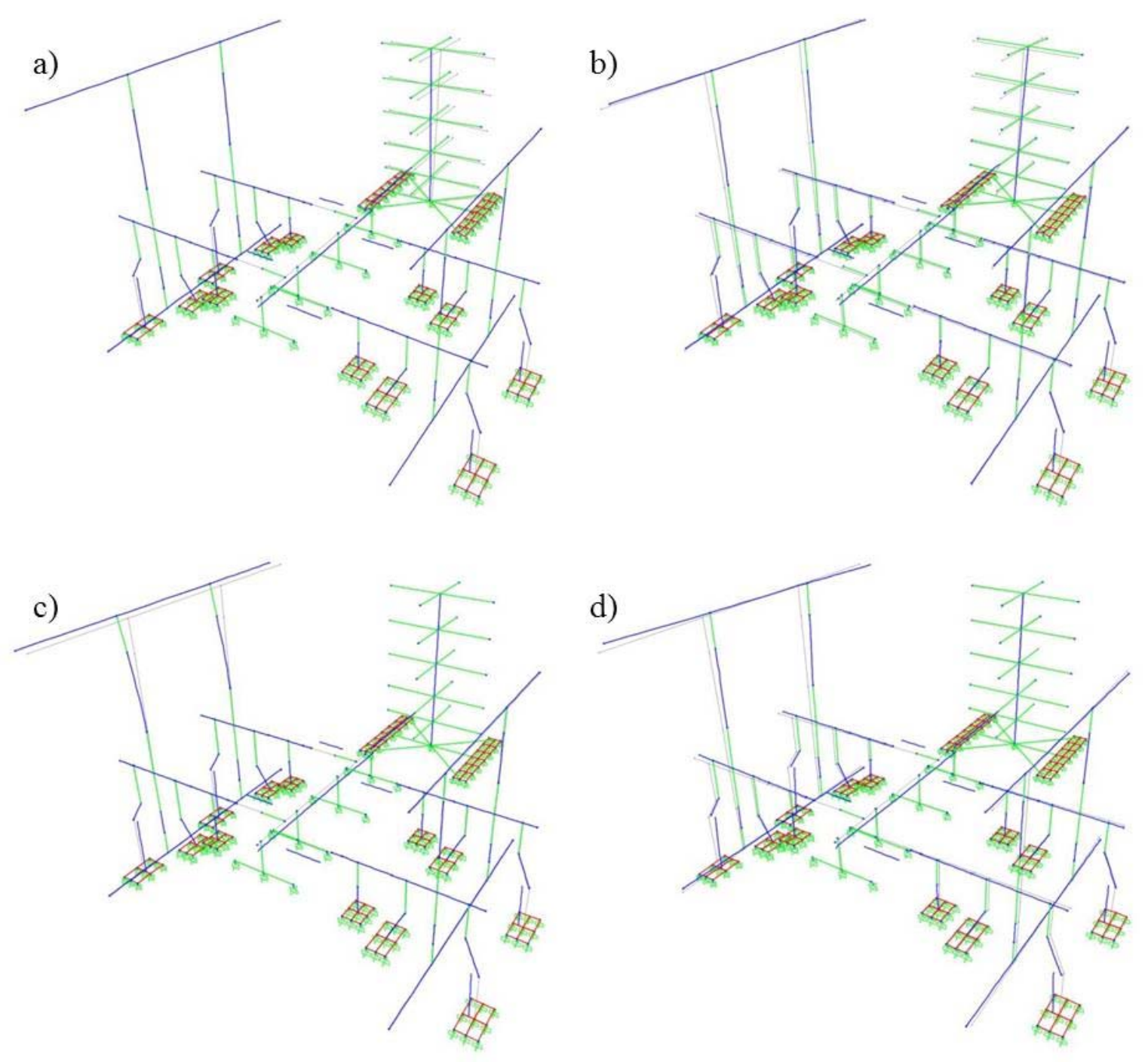

Fig. (9). Modal analysis of BOG compressor : a) mode $1(0.048 \mathrm{sec}), \mathbf{b})$ mode $2(0.038 \mathrm{sec})$, c) mode $3(0.035 \mathrm{sec})$, and d) mode 4 (0.032 sec).

fundamental period is as small as $0.048 \mathrm{sec}$. The vibration of the main motor governs the first mode. The second mode involves the vibrations of the main motor, the dampers, and the cylinders. The vibrations of the dampers and the cylinders govern the third mode. The fourth mode involves the torsional vibrations of the dampers and the cylinders. From the eigenvalue analysis, we can understand that the vibrations of the main motor, and the dampers and cylinders are independent to each other. It should be noted that the flywheel, one of the main components of the compressor, does not contribute much to the first four vibrational modes.

\subsubsection{Understanding the Structural Behavior of the Com- pressor}

The focus of the structural behavior of the compressor is on the anchor bolts since they are designed to be the most vulnerable components to an earthquake loading due to the ductile design concept. The flywheel is a squat equipment that is anchored to the foundation over a wide area. When a lateral force is applied, the sliding motion of the dampers and cylinders are resisted by the anchor bolts of the flywheel as well as their own anchor bolts since the dampers and the cylinders are directly connected to the flywheel. On the other hand, the behavior of the main motor is sliding and overturning as it is relatively tall and the center of gravity is high. Consequently, the anchor bolts of the main motor are subjected to the shear and tensile forces. It should be noted that the main motor is connected to the flywheel only through the crankshaft and their vibrational behaviors are independent as mentioned earlier. In summary, the forces in the anchor bolts at the flywheel and main motor are the most critical ones and, therefore, monitored throughout the analyses. The analyses results indicate that the combination of the tensile and shear forces in the anchor bolts at the main motor are larger than those at the flywheel.

When the design level earthquake $(0.2 \mathrm{~g}$ and $0.13 \mathrm{~g}$ PGAs in the horizontal and vertical directions, respectively) is applied, stresses in all anchor bolts are calculated as those within the elastic range. In this case, the largest stress in the anchor bolt is less than $10 \%$ of the yield strength. In conclusion, the BOG compressor is evaluated as seismically safe against the design earthquake. Fig. (10) shows time histories of a nodal displacement at the top of the BOG compressor and tensile and shear forces at an anchor bolt when an earthquake with $1.0 \mathrm{~g}$ PGA is applied. 


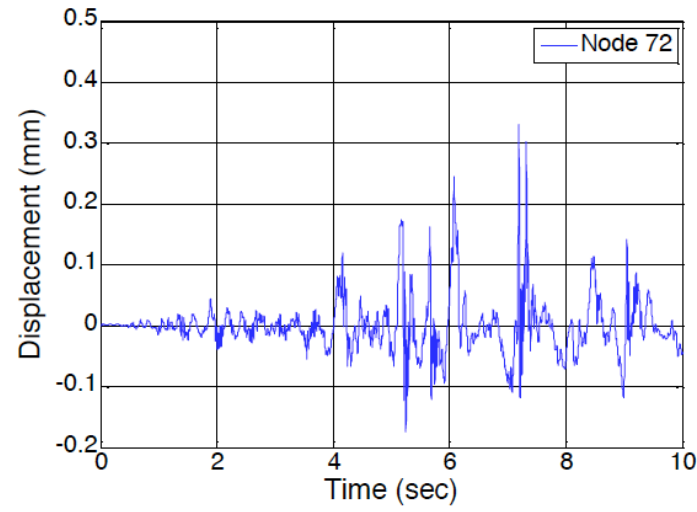

(a)

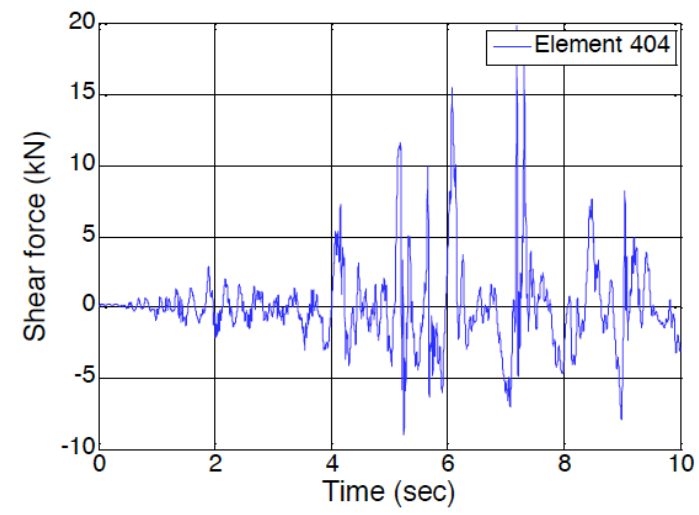

(c)

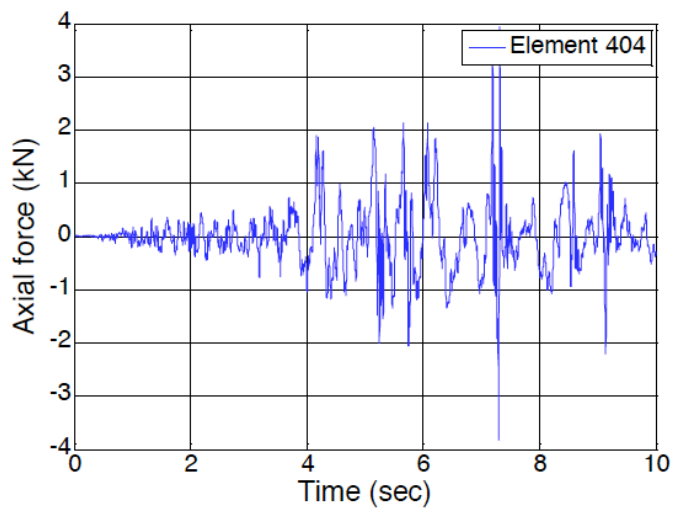

(b)

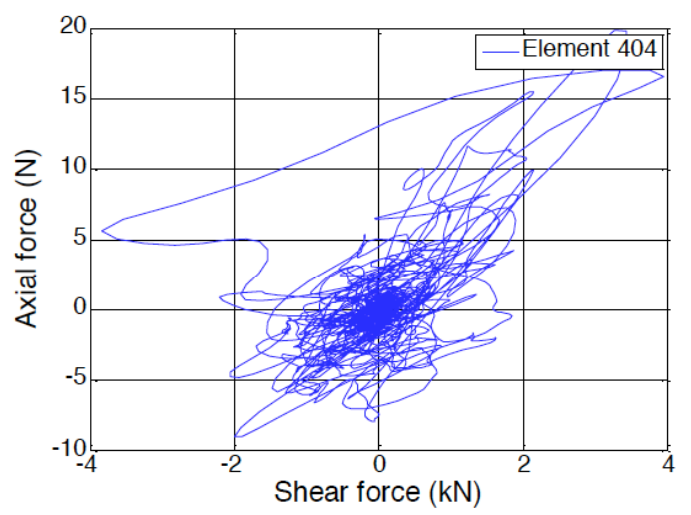

(d)

Fig. (10). Response time histories: (a) displacement at the top of the BOG compressor, (b) axial force in an anchor bolt, (c) shear force in an anchor bolt, and (d) shear force-tension diagram.

\section{SEISMIC FRAGILITY FUNCTION}

Seismic fragility is the conditional probability of a failure of a structural system given a specified earthquake intensity. Here, the failure of a structural system is defined as a damage measure that exceeds a specified threshold as well as a physical collapse of the structure. Fragility curves can be categorized into four groups [19] depending on how the damage data are obtained: empirical, judgmental, analytical, and hybrid which combines the prior three. Even though empirical and judgmental fragility curves may be more realistic, they are limited and analytical methods are widely used for the development of seismic fragility curves [20]. Analytical methods are further categorized depending on whether an analytical function or simulation is used. In the former method, the seismic fragility curve is explicitly expressed as an analytical function of the intensity of earthquakes. In the latter method, seismic fragility curves can be obtained through more rigorous structural analysis combined with simulation methods (e.g., Monte Carlo simulation) to generate random variables. The maximum likelihood estimation method is one of the simulation-based approaches as explained in the following subsection.

\subsection{Maximum Likelihood Estimation Method}

Among several methods to develop seismic fragility curves, the maximum likelihood estimation (MLE) approach proposed by Shinozuka et al. [5, 6] is used in this study. In this approach, the fragility function is assumed as a log-normal cumulative distribution function (CDF) expressed by

$F_{k}(a)=\Phi\left[\frac{\ln \left(a / c_{k}\right)}{\zeta_{k}}\right]$

where $a$ is the earthquake intensity, namely PGA in this study, $c_{k}$ and $\zeta_{k}$ are the median and the log-standard deviation of the log-normal CDF, and $\Phi\{\bullet\}$ is the standard normal CDF. In Eq. 1, the subscript $k$ indicates the $k$-th limit state when more than one limit state is considered. $c_{k}$ and $\zeta_{k}$ are determined by the MLE approach.

The likelihood function is defined by

$L=\prod_{i=1}^{N}\left[F_{k}\left(a_{i}\right)\right]^{x_{i}}\left[1-F_{k}\left(a_{i}\right)\right]^{\left(1-x_{i}\right)}$

where $F_{k}(a)$ increases when damage occurs and $1-F_{k}(a)$, the probability of not experiencing a damage, increases when damage does not occur for the earthquake intensity of $a_{i}$. In Eq. 2, $N$ is the number of ground motions considered and $x_{i}$ is a Bernoulli random variable that indicates whether the structure is damaged or not where 0 indicates no damage and 1 indicates damage. $c_{k}$ and $\zeta_{k}$ are determined so that Eq. 2 is maximized with respect to $c_{k}$ and $\zeta_{k}$ as follows

$\frac{\partial L}{\partial c_{k}}=\frac{\partial L}{\partial \zeta_{k}}=0, \quad k=1, \cdots, N$ 
Table 3. Limit states of anchor bolts.

\begin{tabular}{|c|c|c|}
\hline \multirow{2}{*}{ Category } & Abbreviation & Descriptions for the Limit State \\
\hline \hline \multirow{2}{*}{ Tensile failure } & T1 & Yield strength in tension, 248 MPa \\
\cline { 2 - 3 } & T2 & Ultimate strength in tension, 400 MPa \\
\hline \multirow{2}{*}{ Shear failure } & SLS1 & Yield strength in shear, 183 MPa \\
\cline { 2 - 3 } & SLS2 & Ultimate strength in shear, 230 MPa \\
\hline \multirow{2}{*}{ Shear-tension interaction failure } & ILS1 & Yield strength in the shear-tension interaction diagram, Eq. 4 \\
\cline { 2 - 3 } & ILS2 & Ultimate strength in the shear-tension interaction diagram, Eq. 4 \\
\hline
\end{tabular}

\subsection{Limit States}

The anchor bolts are fixed to the cast-in-place foundation of the BOG compressor. The anchor bolt-foundation system is designed such that the foundation or pedestal concrete has enough breakout capacity, pullout strength, and side-face blowout capacity. Therefore, the anchor bolts are designed to yield before any kind of damage to the concrete happens. This leads to the ductile behavior of the BOG compressor. Consequently, it is reasonable to assume that the damage is localized only to the anchor bolts when an earthquake occurs.

The limit states of the anchor bolts are categorized by the shear failure, tensile failure, and shear-tension interaction failure. In each category, the yield and ultimate strengths define the limit states. Accordingly, six limit states are defined for the BOG compressor as shown in Table $\mathbf{3}$. The tensile strengths are determined by the steel material model. The shear strengths are determined by the pushover analysis as mentioned earlier. The interaction failure is defined by the formula recommended by American Lifeline Alliance [21] as

$\left(\frac{P}{P_{c}}\right)^{n}+\left(\frac{V}{V_{c}}\right)^{n}<1$

where $P$ and $V$ are the tensile and shear forces acting in the anchor bolt and $P_{c}$ and $V_{c}$ are the tensile and shear strengths. $P_{c}$ indicates the yield strength or the ultimate strength in tension and $V_{c}$ indicates the corresponding yield strength or the ultimate strength in shear. The power $n$ is suggested as 1, $5 / 3$, and 2 in several guidelines such as UBC-97 [12], NEHRP 97 [22], ASCE-7 [23], and ACI 318 [24]. In this study, 2 is arbitrarily selected for $n$.

\subsection{Seismic Fragility Functions of the BOG Compressor}

To develop a seismic fragility function, the performance of the BOG compressor needs to be evaluated over a wide range of earthquake intensities. At a specific PGA level, the sample rate of failure, i.e. $x$ out of 20 cases failed, of exceeding the limit state is calculated and the fragility function is estimated using the MLE method.

Fig. (11) shows the seismic fragility curves for the two limit states for the tension failure criteria, namely TLS1 and TLS2 representing yielding and ultimate limit states, respectively. For TLS1, the failure probability is larger than zero at $3.5 \mathrm{~g}$ or larger PGA, $50 \%$ at $4.4 \mathrm{~g} \mathrm{PGA}$, and $90 \%$ at $5.0 \mathrm{~g}$
PGA. For TLS2, the failure probability is larger than zero at $5.5 \mathrm{~g}$ or larger PGA, $50 \%$ at $7.0 \mathrm{~g}$ PGA, and $90 \%$ at $7.8 \mathrm{~g}$ PGA. In most cases, the failure of the anchor bolt Type E used in the main motor occurred.

Fig. (12) shows the seismic fragility curves for the two limit states for the shear failure criteria, namely SLS1 and SLS2 representing yielding and ultimate limit states, respectively. For SLS1, the failure probability is larger than zero at $3.0 \mathrm{~g}$ or larger PGA, $50 \%$ at $4.8 \mathrm{~g} \mathrm{PGA}$, and $90 \%$ at $6.2 \mathrm{~g}$ PGA. For SLS2, the failure probability is larger than zero at $6.3 \mathrm{~g}, 50 \%$ at $7.5 \mathrm{~g} \mathrm{PGA}$, and $90 \%$ at $8.2 \mathrm{~g}$ PGA. In most cases, the failure of the anchor bolt Type A used in the flywheel occurred.

Fig. (13) shows the seismic fragility curves for the two limit states for the shear-tension interaction failure criteria, namely ILS1 and ILS2 representing yielding and ultimate limit states, respectively. For ILS1, the failure probability is larger than zero at $3.4 \mathrm{~g}$ or larger PGA, 50\% at $3.8 \mathrm{~g} \mathrm{PGA,}$ and $90 \%$ at $4.1 \mathrm{~g}$ PGA. For ILS2, the failure probability is larger than zero at $5.2 \mathrm{~g}$ or larger PGA, $50 \%$ at $6.3 \mathrm{~g} \mathrm{PGA}$, and $90 \%$ at $7.1 \mathrm{~g}$ PGA.

Fig. (14) shows the comparison of the seismic fragility curves for the three limit states for the yielding criteria, i.e. TLS1, SLS1, and ILS1. It is observed that the non-zero failure probability starts at a range of 3.0 to $3.5 \mathrm{~g}$ PGA while $100 \%$ failure probability ranges from $4.3 \mathrm{~g}$ to $8.0 \mathrm{~g}$. It is noted that the 'inclination' of three curves are different, which means that their levels of uncertainty of estimating the failure are different, where a stiffer curve is less uncertain. It should be also noted that the fragility curve for TLS 1 is on the left hand side of that of SLS1, which means that the BOG compressor is more likely to experience the tensile yielding of anchor bolts before the shear yielding. It agrees with the ductile design concept.

Fig. (15) shows the comparison of the seismic fragility curves for the three limit states for the ultimate criteria, i.e. TLS2, SLS2, and ILS2. It is noted that the 'inclination' of the three curves are similar to each other, which means that their levels of uncertainty of estimating the failure are similar. In overall, the BOG compressor is not likely to get any damage under a considerably big earthquake. Table 4 lists the medians, log-standard deviations, and coefficient of variations (COVs, the ratio of the standard deviation to the median) for fragility functions of various limit states. 


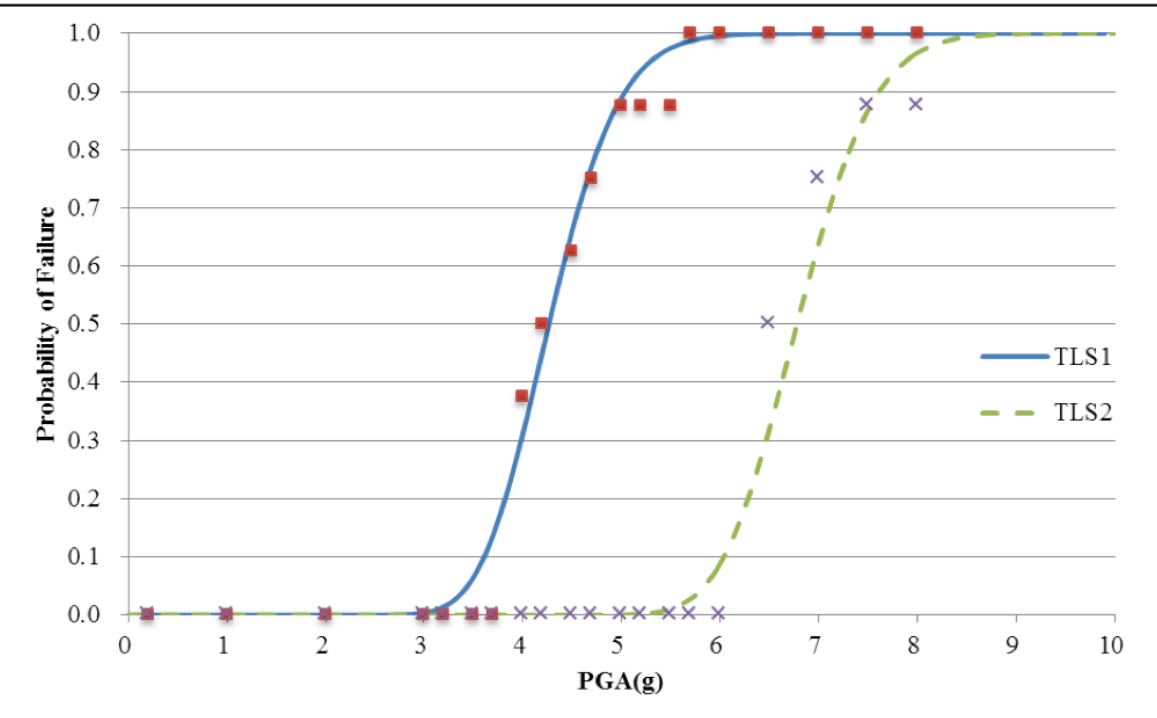

Fig. (11). Seismic fragility curve of the anchor bolt considering tension failure.

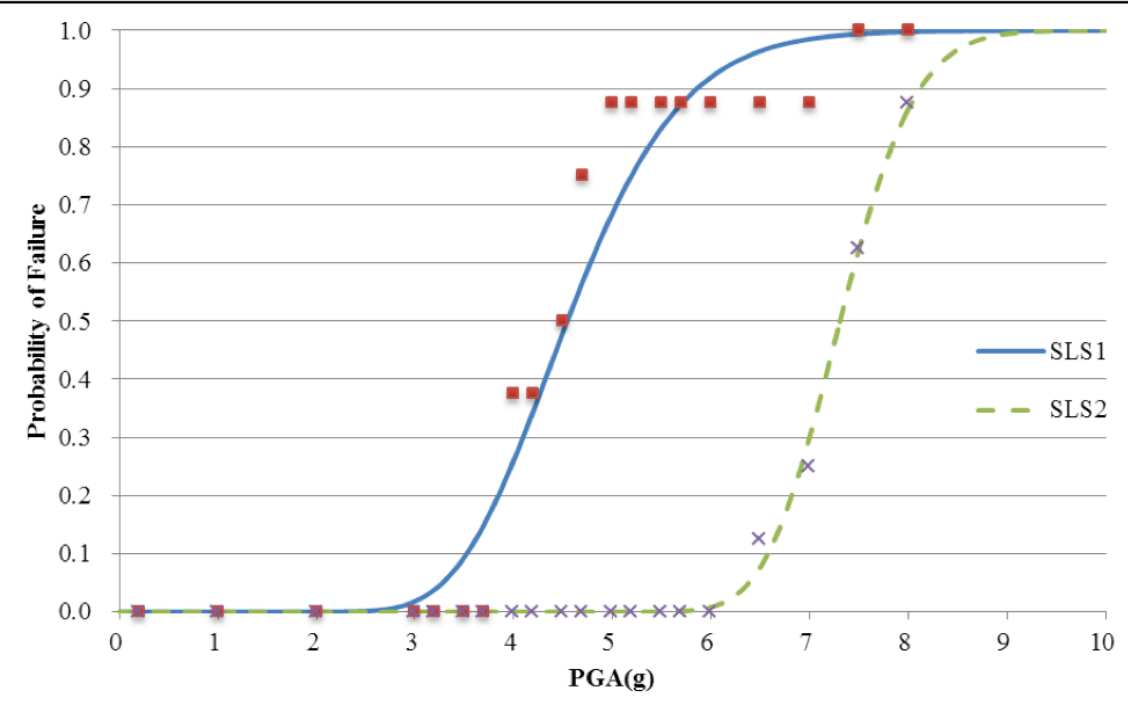

Fig. (12). Seismic fragility curve of the anchor bolt considering shear failure.

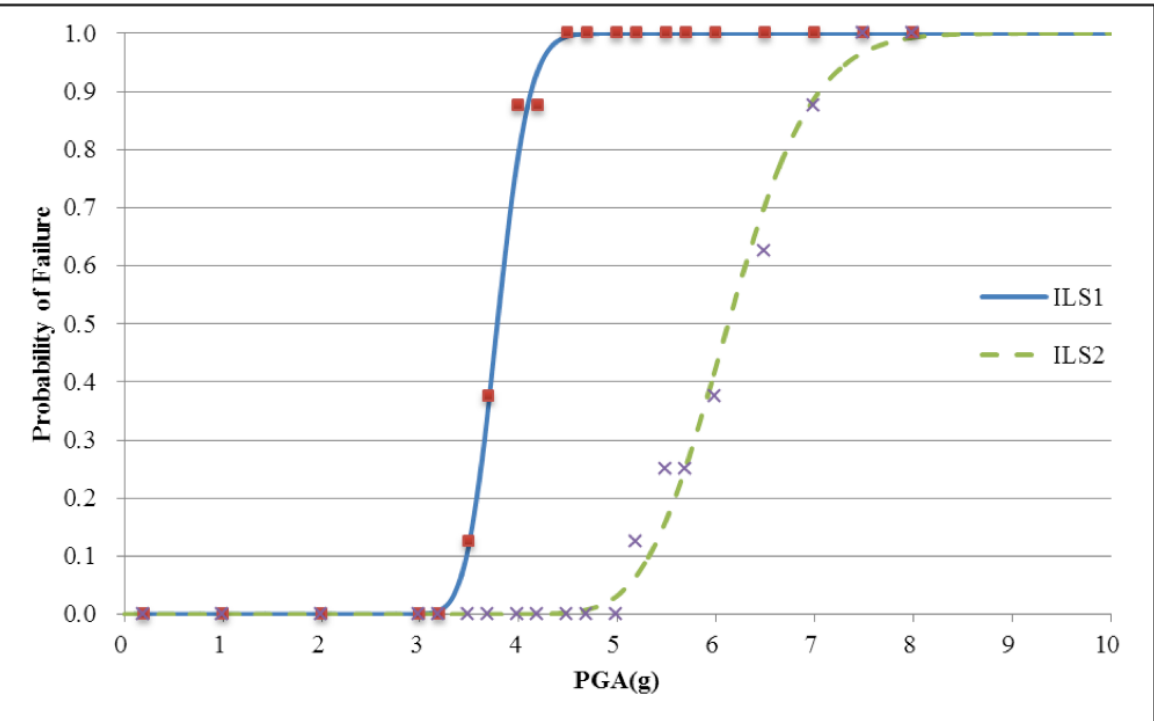

Fig. (13). Seismic fragility curve of the anchor bolt considering the shear-tension interaction failure. 


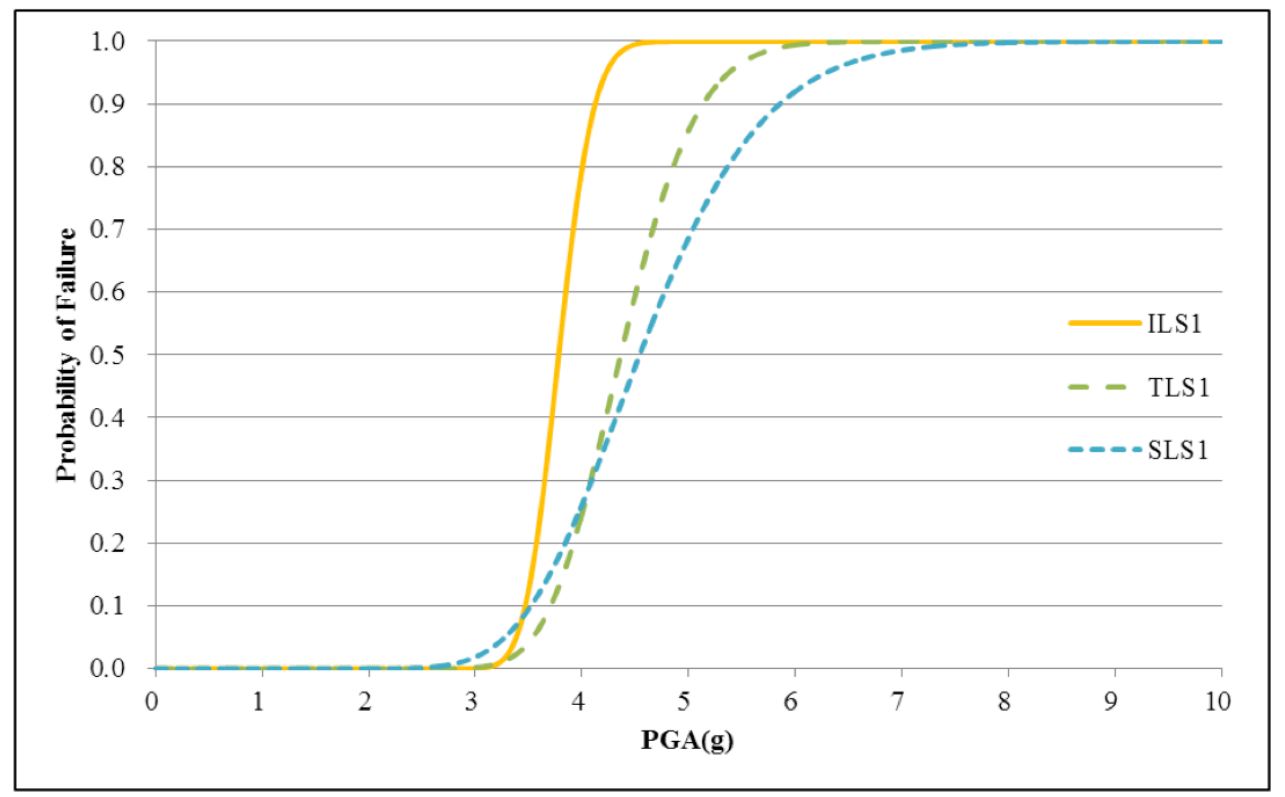

Fig. (14). Seismic fragility curves of the anchor bolt considering the yielding failure criteria.

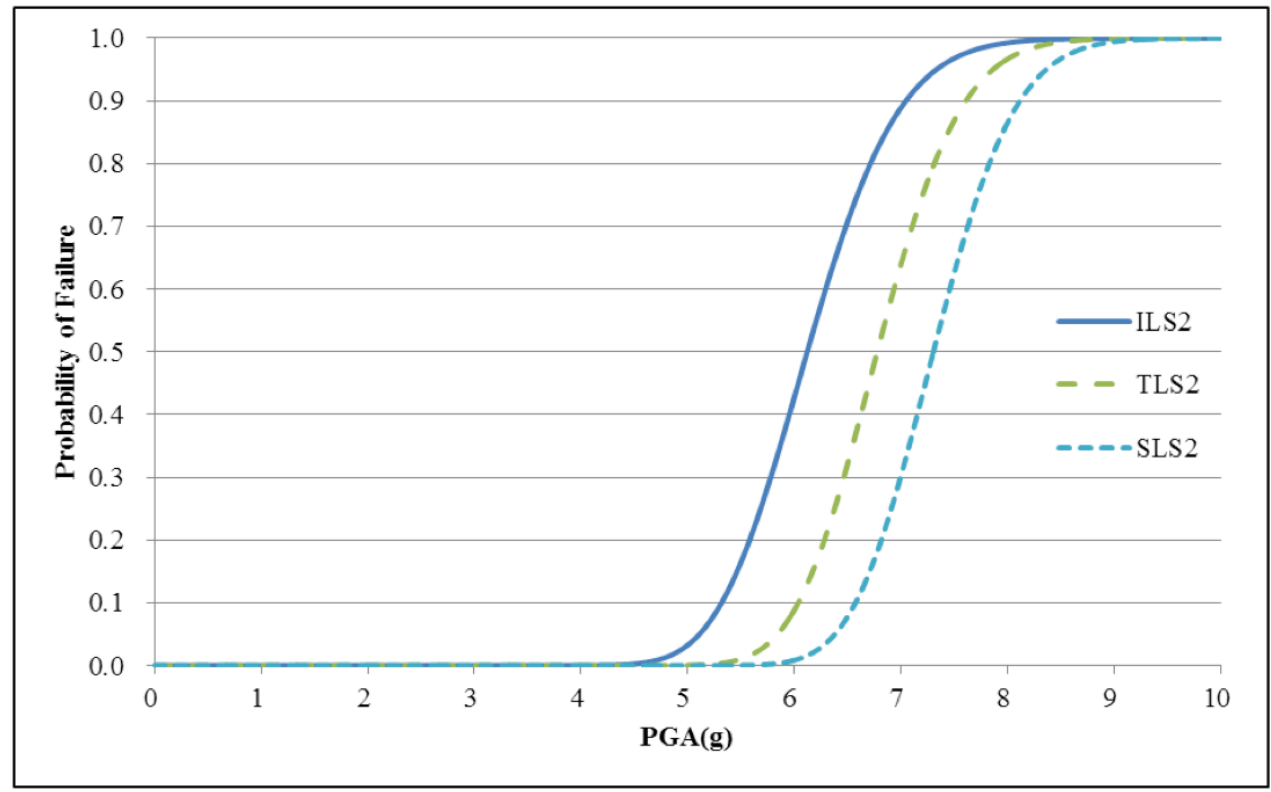

Fig. (15). Seismic fragility curves of the anchor bolt considering ultimate failure criteria.

Table 4. Probability distribution characteristics of fragility curves.

\begin{tabular}{|c|c|c|c|c|}
\hline \multirow{2}{*}{ Limit State } & $\boldsymbol{a}_{\boldsymbol{i}}(\mathbf{g})$ & Z (g) & Coefficient of Variation \\
\hline \hline \multirow{2}{*}{ Tension } & TLS1 & 4.3326 & 0.1031 & $2.7 \%$ \\
\cline { 2 - 5 } & TLS2 & 6.8934 & 0.0915 & $1.3 \%$ \\
\hline \multirow{2}{*}{ Shear } & SLS1 & 4.7072 & 0.1961 & $4.2 \%$ \\
\cline { 2 - 5 } & SLS2 & 7.3591 & 0.0713 & $1.0 \%$ \\
\multirow{2}{*}{ Shear-tension interaction } & ILS1 & 3.7542 & 0.0565 & $1.5 \%$ \\
\cline { 2 - 5 } & ILS2 & 6.2312 & 0.0916 & $1.4 \%$ \\
\hline
\end{tabular}


Table 5. Uncertainty in the Ground motion profile in terms of statistics of spectral accelerations.

\begin{tabular}{|c|c|c|c|}
\hline Natural Period (sec) & Mean $(\mathrm{g})$ & Standard Deviation (g) & Coefficient of Variation (\%) \\
\hline \hline 0.035 & 0.243 & 0.0524 & 21.6 \\
\hline 0.038 & 0.251 & 0.0636 & 25.3 \\
\hline 0.048 & 0.275 & 0.0882 & 32.0 \\
\hline
\end{tabular}

\subsection{Propagation of Uncertainty}

COVs in Table 4 ranges from $1.0 \%$ to $4.2 \%$. COV is a measure of uncertainty in estimating the failure of the structure. The source of this uncertainty of fragility functions is only the uncertainty in the ground motions because the structural model is deterministic. In the process of developing fragility curves, the seismic intensity, i.e., PGA is controlled and the other characteristics in the ground motion are left uncertain. Although we did not identify and quantify those uncertainties in the ground motion, they are reflected to the fragility curves in an integrated sense.

Table 5 shows the means, standard deviations, and COVs (the ratio of the standard deviation to the mean, in this case) of spectral accelerations of the 20 ground motions evaluated at the first three natural periods of the BOG compressor. It is observed that the COVs range from $21.6 \%$ to $32.0 \%$. The comparison of COVs of the input ground motions and those of the output fragility functions leads to the conclusion that the uncertainty in the ground motion is decreased when developing the fragility function.

\section{CONCLUSION}

The seismic performance of the BOG compressor in operation in Korea is evaluated in this study. A 3-D finite element model of the compressor is developed to understand its dynamic characteristics. A suite of 20 recorded ground acceleration time histories are selected and a series of time history analyses are conducted over a wide range of PGA. Seismic fragility functions are developed based on the MLE approach with respect to various limit states of the anchor bolt failure. The following conclusions are drawn from this study.

- When an earthquake load is applied to the BOG compressor, the main motor is likely to overturn and the flywheel is likely to slide, and, consequently, anchor bolts will be subjected to tension and shear, respectively.

- The uncertainty in the ground motion propagates to the uncertainty in estimating the failure of the BOG compressor in a decreasing manner.

- The anchor bolts will likely yield to tension before they yield to shear, which is a desirable and ductile failure mechanism.

- When the design level earthquake (0.2 g horizontal PGA and $0.13 \mathrm{~g}$ vertical PGA) occurs the probability of the BOG compressor experiencing any damage is near $0.0 \%$.

- The BOG compressor will not likely to receive any damage from an earthquake of $3.0 \mathrm{~g}$ or less PGA.
It should be noted that the conclusions are based on the specific BOG compressor examined in this study, and consequently, it must be carefully reviewed before a generalization. The result of this study will be useful to evaluate the seismic vulnerability of an LNG terminal if combined with fragility functions of the other major process facilities.

\section{CONFLICT OF INTEREST}

The authors confirm that this article content has no conflict of interest.

\section{ACKNOWLEDGEMENTS}

This research was supported by a grant 'Development of Seismic Fragility for Urban Infrastructure Network' [NEMA-NH-2012-68] from the Natural Hazard Mitigation Research Group, National Emergency Management Agency of Korea.

\section{REFERENCES}

[1] D. Seyedi, P. Gehl, J. Douglas, L. Davenne, N. Mezher, and S Ghavamian, "Development of seismic fragility surfaces for reinforced concrete buildings by means of nonlinear time-history analysis," Earthquake Engineering and Structural Dynamics, vol. 39, pp. 91-108, 2010.

[2] B. G. Nielson, and R. DesRoches, "Seismic fragility methodology for highway bridges using a component level approach," Earthquake Engineering and Structural Dynamics, vol. 36, no. 6, pp. 823-839, 2007.

[3] F. Perotti, M. Domaneschi, and S. De Grandis, "The numerical computation of seismic fragility of base-isolated nuclear power plants buildings," Nuclear Engineering and Design, vol. 262, pp. 189-200, 2013.

[4] A. M. Kaynia, Ed., SYNER-G Reference Report 4: Guidelines for deriving seismic fragility functions of elements at risk: buildings, lifelines, transportation networks and critical facilities. European Commission, 2013. [Online]. Available: http://www.vce.at/ SYNER-G/files/dissemination/referencereports.html [Accessed: $15^{\text {th }}$ Dec. 2011].

[5] M. Shinozuka, M. Q. Feng, H. K. Kim, and S. H. Kim, "Nonlinear static procedure for fragility curve development," Journal of Engineering Mechanics, ASCE, vol. 126, no. 12, pp. 1287-1295, 2000.

[6] M. Shinozuka, M. Q. Feng, J. H. Lee, and T. Naganuma, "Statistical analysis of fragility curves," Journal of Engineering Mechanics, ASCE, vol. 126, no. 12, pp. 1224-1231, 2000.

[7] S. Higuchi, T. Mori, T. Matsuda, Y. Goto, B. L. Kutter, H. Akiyama, K. Toki, and M. Kobayashi, "Seismic performance of LNG storage tank foundations during the very large earthquake," In: $12^{\text {th }}$ World Conference on Earthquake Engineering (12WCEE), Auchland, New Zealand, 2000, paper no. 2587.

[8] R. Zhang, D. Weng, and R. Xiaosong, "Seismic analysis of a LNG storage tank isolated by a multiple friction pendulum system," Earthquake Engineering and Engineering Vibration, vol. 10, pp. 253-262, 2011.

[9] P. K. Malhotra, T. Wenk, and M. Wieland, "Simple procedure for seismic analysis of liquid-storage tanks," Structural Engineering International, vol. 3, pp. 197-201, 2000. 
[10] Federal Emergency Management Agency, "Earthquake Resistant Construction of Gas and Liquid Fuel Pipeline Systems Serving or Regulated by the Federal Government", FEMA-233, 1992.

[11] Draft FERC Seismic design guidelines and data submittal requirements for LNG facilities, Federal Energy Regulation Committee, 2007.

[12] Uniform Building Code”, International Code Council, 1997.

[13] NFPA 59A: Standard for the Production, Storage, and Handling of Liquefied Natural Gas (LNG)", National Fire Protection Association, 2013

[14] Y. -M. Yang, J. -H. Kim, H. -S. Seo, K. Lee, and I. -S. Yoon, "Development of the world's largest above-ground full containment LNG storage tank," In: $23^{\text {rd }}$ World Gas Conference, June 5-9, Amsterdam, 2006, pp. 2508-2521.

[15] B. M. Jin, S. J. Jeon, S. W. Kim, Y. J. Kim, and C. H. Chung, "Earthquake response analysis of LNG storage tank by axisymmetric finite element model and comparison to the results of the simple model," In: $13^{\text {th }}$ World Conference on Earthquake Engineering, Vancouver, B. C., Canada, August 1-6, 2004, Paper No. 394.

[16] Computers and Structures Inc., "Analysis reference manual for SAP2000 ETABS, SAFE, and CSiBridge", Berkeley, CA, USA, 2013.
[17] T. Kubr, and P. Zeman, "Seismic response of machines with rotating parts," PVP-Vol. 428-1, Seismic Engineering, Proceedings of the 2001 ASME Pressure Vessels and Piping Conference, Atlanta, Georgia, July 22-26, 2001, pp. 97-100, 2001.

[18] PEER Strong Motion Database, Available: http://peer.berkeley.edu/ nga/ [Accessed June 28, 2014].

[19] T. Rossetto, and A. S. Elnashai, "Derivation of vulnerability functions for European-type RC structures based on observational data", Engineering Structures, vol. 25, no. 10, pp. 1241-1263, 2003.

[20] Y. -J. Lee, and D. -S. Moon, "A new methodology of the development of seismic fragility curves", Smart Structures and Systems, vol. 14, no. 5, pp. 847-867, 2014.

[21] Guide for Seismic Evaluation of Active Mechanical Equipment", American Lifelines Alliance, October 2004.

[22] Building Seismic Safety Council, NEHRP Recommended Provisions for Seismic Regulations for New Buildings and Other Structures (FEMA 302)", Federal Emergency Management Agency, 1997.

[23] Minimum Design Loads for Buildings and Other Structures (ASCE/SEI 7-10)", American Society of Civil Engineers, 2010.

[24] Building Code Requirements for Structural Concrete (ACI 31811)", American Concrete Institute, 2011.

(C) Park and Lee; Licensee Bentham Open.

This is an open access article licensed under the terms of the Creative Commons Attribution Non-Commercial License (http://creativecommons.org/licenses/ by-nc/3.0/) which permits unrestricted, non-commercial use, distribution and reproduction in any medium, provided the work is properly cited. 